* Doutora e Mestre em Direito pela Universidade Federal do Pará - UFPa. Advogada regularmente inscrita na $\mathrm{OAB} / \mathrm{Pa}$. Professora Titular da Universidade da Amazônia - UNAMA/SER onde leciona na graduação e pós graduação stricto senso. Membro do IBDP - Instituto Brasileiro de Direito Processual Civil e do IBERC - Instituto Brasileiro de Estudos em Responsabilidade Civil. Membro da Associação Norte Nordeste de Processo - ANEEP. Líder do Grupo de Pesquisa com registro no $\mathrm{CNPq}$ "Teorias Gerais do Processo: o Processo como instrumento de realização dos direitos fundamentais". Coordenadora do projeto de pesquisa "A virada tecnológica do direito processual e a realização dos direitos fundamentais. Membro do Comitê de Ética e Pesquisa do ICESUNAMA.E-mail: agathadcpc@ yahoo.com.br

\footnotetext{
**Doutora em Direitos Humanos pela Universidade de Salamanca (Espanha). Mestre em Direitos Fundamentais pela Universidade da Amazônia (UNAMA/PA). Professora do Curso de Graduação e Pós-Graduação em Direito do Centro Universitário do Pará (CESUPA). Líder do Grupo de Pesquisa Trabalho Decente do CESUPA, com registro no Diretório dos Grupos de Pesquisa do CNPq. Auditora do Tribunal de Contas do Estado do Pará (TCE/ PA).E-mail: vanessarochaf@gmail. com
}

\section{Planejamento empresarial e tributário de Startups: DEFINIÇÕES E CARACTERÍSTICAS ESPECIIFICAS}

\author{
BUSINESS AND TAX PLANNING OF STARTUPS: DEFINITIONS \\ AND SPECIFIC CHARACTERISTICS
}

\section{Agatha Gonçalves Santana* Vanessa Rocha Ferreira**}

Como citar: SANTANA, Agatha Gonçalves; FERREIRA, Vanessa Rocha; SILVA, Reginaldo Costa da. Planejamento empresarial e tributário de Startups: definições e características específicas. Revista do Direito Público, Londrina, v. 16, n. 2, p. 126-143, ago. 2021. DOI 10.5433/24157-108104-1.2021v16n 2p. 126. ISSN: $1980-511 \mathrm{X}$

Resumo: Texto que se propõem a analisar aspectos específicos do planejamento empresarial e tributário do novo modelo de empresas conhecido como startups. O objetivo central deste artigo é demonstrar a necessidade de modernização de critérios de planejamentos que são utilizados por empresas tradicionais. A metodologia aplicada é do tipo teórica, nos seus subtipos bibliográfica e documental, utilizando-se dos critérios de análise qualitativa e aplicando-se o método de análise predominantemente dedutivo. Ao final, defende-se que o adequado planejamento empresarial e tributário permite o correto desenvolvimento jurídico e econômico das empresas, especialmente no caso das startups, modelo com características únicas, face ao uso das tecnologias e da utilização diferenciada do seu capital.

Palavras-chave: Planejamento empresarial; Planejamento tributário; Startups.

Abstract: This paper intends to analyse the legal specific aspects of business and tax planning, within the new business stages of companies known as startups. The main objective of this article is to demonstrate the need to modernize the planning that is used by traditional companies. The applied methodology is of the theoretical type, in its bibliographic and documentary aspects, using the qualitative analysis criteria and applying the predominantly deductive analysis method. In the end, it is argued that adequate business and tax planning allows the legal and economic development of companies, especially in the case of 
startups, a model with unique characteristics, in view of the use of technologies and differentiated use of their capital.

Keywords: Business planning; Tax planning; startups. 


\section{INTRODUÇÃO}

O fenômeno econômico conhecido como startups é considerado como um modelo de negócio disciplinado pelo Direito Empresarial, e não como um tipo diferenciado de sociedade empresária ou forma de exercício da atividade, e, como toda inovação, enfrenta dificuldades, uma vez que possui características próprias.

Esse fenômeno teve início em meados do Século XX, no cerne do que é visto como o epicentro gravitacional da era da tecnologia da informação, uma revolução que, desde os anos 1950, vem transformando hábitos e sobretudo mercados no mundo inteiro, no grande polo de inovação do Vale do Silício (Silicon Valey), na Califórnia, Estados Unidos da América.

Nesse contexto, um dos principais instrumentos utilizado para diminuir os problemas sobre as atividades empresariais tornando-as mais eficientes e rentáveis, dentro de um determinado ordenamento jurídico, é o planejamento empresarial, que está necessariamente atrelado ao planejamento tributário. Esses instrumentos são utilizados com forma de reorganizar legalmente a empresa para diminuir, retardar ou extinguir ônus burocráticos e/ou fiscais das atividades empresariais.

No Brasil, o fenômeno das startups tem significativa representação na circulação de renda e na geração de empregos, porém, constata-se que esse modelo de negócio sofre diversas dificuldades práticas, principalmente no que tange a aspectos tributários e trabalhistas. Em virtude disso, a solução de questões relativas ao planejamento empresarial e tributário tende a repercutir de forma positiva, não apenas no âmbito social com a geração de emprego e renda, mas também pode diminuir o número de lides entre investidores e o fisco, bem como o número de procedimentos administrativos no âmbito de órgãos e entidades como o CARF (Conselho Administrativo de Recursos Fiscais) e os TARF's (Tribunais administrativos de recursos fiscais).

Este estudo tem como problema de pesquisa o seguinte questionamento: O modelo de planejamento empresarial e tributário utilizado em uma startup deve ser, ainda que de certa forma, diferente do utilizado em uma empresa tradicional?

Acerca do objeto de estudo levantam-se as seguintes questões norteadoras: Quais as dificuldades e características específicas das startups, e como elas interferem em seu planejamento tributário?

Assim, o objetivo geral desta pesquisa é investigar se é necessário reanalisar o modelo de planejamento tributário de empresas tradicionais, em suas especificidades, para melhor atender ao desempenho de uma startup.

A metodologia utilizada na pesquisa é do tipo teórica, nos seus subtipos de pesquisa documental pura, de análise bibliográfica de doutrina e legislação nacionais, principalmente, a Lei Complementar $n^{\circ} 123$, que traz definições de micro e pequenas empresas e estabelece o regime tributário diferenciado dessas, o Simples Nacional. Utilizou-se essencialmente o método de argumentação dedutivo.

Estruturalmente o presente trabalho encontra-se dividido em cinco itens, sendo o primeiro 
esta introdução. O segundo, conceitual, que traz as definições e limites do planejamento empresarial; o terceiro item, histórico, que analisa a origem desse novo modelo de negócio - as startups no Brasil e no mundo, destacando a sua importância para a economia brasileira. O quarto item destaca a importância do planejamento empresarial e tributário para as startups, o que as ajuda, de modo lícito, a evitar gastos desnecessários. Por fim, apresenta-se uma breve conclusão sobre a necessidade de adequação dos modelos tradicionais de planejamentos jurídicos para atender aos anseios desse novo tipo negocial.

\section{PLANEJAMENTO EMPRESARIAL E TRIBUTÁRIO: definição e limites}

De acordo com Ackoff (1974, p. 1), planejamento é "[...] a definição de um futuro desejado e meios eficazes de alcançá-lo.”. Desta forma, é possível extrair do conceito mencionado o binômio de todo planejamento: 1. Definição dos objetivos e, 2. Definição dos meios (instrumentos e técnicas) que serão usados para o alcance de tais objetivos.

Um dos principais e mais importantes instrumentos utilizados para diminuir problemas sobre as atividades empresariais, tornando-as mais eficientes e rentáveis é o planejamento empresarial, diretamente atrelado a um necessário conhecimento interdisciplinar, que envolve diversos ramos do direito, tais como: o administrativo, o civil e, especialmente, o tributário.

Um planejamento adequado permite que o empresário potencialize os proveitos de sua empresa, de modo a atingir inclusive a sua função social. Todavia, trata-se de um procedimento complexo, que embora difícil de ser realizado, precisa ser útil para quem o idealizou (ACKOFF, 1974).

O Código Civil Brasileiro (BRASIL, 2002), em seu art. 966 define como empresário todo aquele que exerce profissionalmente atividade econômica organizada para a produção ou para a circulação de bens ou de serviços. Infere-se, assim, que é decorrência intrínseca do próprio conceito de empresário a finalidade econômica e, dessa forma, a atividade exercida por uma pessoa só poderá ser definida como empresarial se, dentre outras coisas, possuisse como objetivo fim a geração de lucro.

Nesse sentido, Coelho (2011, p. 32) aponta que:

A atividade empresarial é econômica no sentido de que busca gerar lucro para quem a explora. Note-se que o lucro pode ser o objetivo da produção ou circulação de bens ou serviços, ou apenas o instrumento para alcançar outras finalidades. Religiosos podem prestar serviços educacionais (numa escola ou universidade) sem visar especificamente o lucro. É evidente que, no capitalismo, nenhuma atividade econômica se mantém sem lucratividade e, por isso, o valor total das mensalidades deve superar o das despesas também nesses estabelecimentos. Mas a escola ou universidade religiosas podem ter objetivos não lucrativos, como a difusão de valores ou criação de postos de emprego para os seus sacerdotes. Neste caso, o lucro é meio e não fim da atividade econômica. 
Assim, é possível perceber que o planejamento de uma empresa deve ter como objetivo fim a geração de lucro (mais créditos e menos débitos), propiciando o desenvolvimento da atividade. O ponto que gera maiores questionamentos é como alcançar esse objetivo, ou seja, de que modo e com quais instrumentos e técnicas isso seria possível.

Alguns dos débitos comuns que as empresas possuem estão diretamente relacionados à tributação. Com o intuito de diminuir esses gastos é que surge a chamada elisão fiscal, também conhecida como planejamento jurídico tributário. Como decorrência dessa junção, tem-se a necessária intercessão entre o planejamento tributário e o planejamento empresarial.

Pode-se afirmar, ainda que de maneira sucinta, que a elisão fiscal é uma forma de organizar as atividades realizadas pela empresa de maneira lícita e sem abusos, com a finalidade de excluir, reduzir ou adiar os encargos tributários.

Nesse sentido, Borges (2011, p. 37) define em que consiste a essência do planejamento tributário. Acompanhe:

A natureza ou essência do Planejamento Tributário consiste em organizar os empreendimentos econômico-mercantis da empresa, mediante o emprego de estruturas jurídicas capazes de bloquear a concretização da hipótese de incidência fiscal ou, então, de fazer com que sua materialidade ocorra na medida ou no tempo que lhe sejam mais propícios.

O sistema tributário brasileiro possui como característica uma alta complexidade, com um significativo número de tributos, hipóteses de incidência, regras e exceções. A respeito dessa complexidade, Breda, em artigo publicado no site do Conselho Federal de Contabilidade (CFC), destaca que:

Efetivamente, segundo dados do Instituto brasileiro de Planejamento e Tributação (IBPT), o sistema tributário brasileiro conta com 63 tributos em vigor e 97 obrigações acessórias (conjunto de documentos, registros e declarações utilizadas para o cálculo dos tributos). Essa complexidade, sabemos, é muito desfavorável para o ambiente de negócios, pois, além de onerar as empresas com estruturas especializadas no assunto, contribui para fraudes e evasão fiscal. De acordo com o IBPT, as empresas precisam seguir cerca de 3.790 normas distintas, que mudam com frequência, para estarem em dia com suas obrigações, gerando muita complexidade e insegurança no ambiente de negócios (BREDA, 2018).

Tal planejamento deve ser lícito, ideal, sendo de suma importância para os contribuintes, tendo em vista que ninguém pode ser obrigado a seguir a alternativa que conduza ao maior recolhimento de tributos (ARAUJO, 2018, p. 20-22).

Devido a essa complexidade, mostra-se cada vez mais importante que toda empresa possua um planejamento empresarial e tributário competente, devendo tal planejamento ser integrado à estrutura estratégica da empresa, para que esta se mostre verdadeiramente competitiva, podendo, dessa forma, se manter e se tornar cada vez mais forte no mercado. Assim, evidenciam Siqueira, 
Cury e Gomes (2011, p. 184) que:

O planejamento Tributário tornou-se de fundamental importância para as empresas, devido à legislação tributária brasileira, adotar um número excessivo de leis e de constantes alterações. Portanto passa a ser vista como complexa, o que dificulta aos empresários a promover a interpretação, assim como se manter atualizados em virtude dos diversos influenciadores na gestão empresarial de forma específica.

Embora o planejamento tributário seja um importante instrumento para o mundo empresarial, como já se pôde perceber, ele comporta limites, os quais, quando extrapolados, levam à prática dos institutos da elisão fiscal ou até mesmo da evasão fiscal, ambos proibidos no Brasil e que quando praticados podem gerar sanções fiscais ou mesmo penais, conforme será abordado adiante.

Existe certa divergência na doutrina a respeito da definição dos termos elisão, evasão e elusão fiscal, principalmente no que tange aos dois primeiros. Todavia, a doutrina majoritária, representada, dentre outros, por Alexandre (2017), entende que os três termos dizem respeito a conjuntos de medidas que visam a extinção, diminuição ou adiamento do ônus tributário. O que os diferencia é que evasão fiscal se refere a um conjunto de medidas ilícitas e, a elisão, a um conjunto de medidas lícitas. Sobre o tema, destaca Martins (2014, p. 105):

A elisão, portanto, é procedimento utilizado pelo sujeito passivo da relação tributária objetivando reduzir o peso da carga tributária, pela escolha, entre diversos dispositivos e alternativas da lei, daqueles que lhe permitem pagar menos tributo. Não o mesmo em relação à evasão fiscal, que adentra o campo da sonegação ou falta de recolhimento tributário, haja dolo ou culpa, sendo que na sua faceta dolosa, hão de considerar as formas previstas no Direito pátrio, como de simulação, fraude e sonegação.

Por outro lado, a elusão fiscal, também denominada por vezes de elisão ineficaz ou elisão abusiva, está relacionada a um conjunto de medidas que, embora revestida de uma aparente licitude, esconde no seu interior um abuso de direito. Na prática, isso ocorre com a simulação de um negócio jurídico lícito com o intuito de mascarar a ocorrência do fato gerador tributário.

Sobre este assunto, destaca Alexandre (2017, p. 342):

Por fim, nos casos denominados pela· doutrina de elusão fiscal (elisão ineficaz, ou elisão abusiva), o contribuinte simula determinado negócio jurídico com a finalidade de dissimular a ocorrência do fato gerador. Trata-se de um ardil caracterizado primordialmente pelo que a doutrina denomina de abuso das formas, pois o sujeito passivo adota uma forma jurídica atípica, a rigor lícita, com o escopo de escapar artificiosamente da tributação.

Tal prática, proibida no Brasil, é, segundo Torres (2013), a especificação do princípio geral da vedação do abuso de direito, sendo que, nas palavras de Torres (2013): “A proibição de elisão abusiva no campo tributário nada mais é que a especificação do princípio geral, jurídico e moral, da vedação do abuso de direito". Assim, a partir de 2001, com o advento da Lei Complementar no 
104, a proibição da elisão fiscal abusiva passou a ter previsão expressa no parágrafo único do art. 116, do Código Tributário Nacional (CTN), que assim dispõe:

A autoridade administrativa poderá desconsiderar atos ou negócios jurídicos praticados com a finalidade de dissimular a ocorrência do fato gerador do tributo ou a natureza dos elementos constitutivos da obrigação tributária, observados os procedimentos a serem estabelecidos em lei ordinária (BRASIL, 1966).

Desse modo, percebe-se, portanto, a grande importância do papel do advogado tributarista e do contador, profissionais que devem juntos elaborar o planejamento tributário da empresa e fornecer os elementos informativos necessários para o administrador tomar sempre as melhores decisões, com o intuito de conseguir que o ônus tributário da empresa seja o menor possível, sem, entretanto, praticar condutas que possam ser consideradas ilícitas ou abusivas.

\section{A ORIGEM E EVOLUÇÃO DAS STARTUPS}

As novas tecnologias tornaram a vida cada vez mais dinâmica, rápida e concorrente, impactando, da mesma maneira, no universo empresarial, o que exige que o empreendedor amplie a sua visão de mercado em uma constante busca da renovação e conquista do público-alvo.

Isso porque o que se considera inovação hoje, daqui a alguns meses (ou até mesmo dias) já poderá ser considerado ultrapassado pelo mercado consumidor. Assim, para que a empresa continue atraindo consumidores, o empreendedor deve estar atento às demandas do mercado. Nesse sentido destacam Barbosa, Pimenta e Fonseca (2017, p. 13) que " [...] a empresa que quer permanecer viva, deverá estar totalmente conectada com as demandas do mercado e com as exigências cada vez maiores de seus consumidores".

Deve o empreendedor, para atender tais demandas, além de se preocupar com a criação de novos produtos e serviços, buscar novas formas de organização empresarial. Nesse sentido, Mamede e Mamede (2015, p. 1) afirmam que:

De tempos em tempos, o ambiente empresarial é sacudido por tendências, como denunciam alguns, por modismos que são repetidos como ladainhas e, assim tornam-se obrigações para gestores empresariais. Esses movimentos conceituais, que propões novas posturas na organização e na atuação empresarial, são habitualmente respostas às grandes demandas que se verificam em cada tempo.

Assim, foi no anseio de atender a essas novas demandas que surgiram as chamadas startups, termo inglês que pode ser livremente traduzido como "começar".

O fenômeno econômico das startups teve início por volta do Século XX em meio ao grande polo de inovação localizado na Califórnia, nos Estados Unidos da América, especificamente no Vale do Silício, conhecido como coração da era da tecnologia da informação, e o epicentro de uma revolução que vem transformando, desde os anos 1950, hábitos e sobretudo mercados no mundo inteiro (VALE..., 2019). 
Sobre o tema, acerca das startups como um tipo de negócio, evidencia Falcão (2017, p. 25-26) que:

A origem deste fenômeno econômico denominado Startup data da segunda metade do Século XX nos EUA, surgido no centro da indústria de venture capital do Silicon Valley (ou Vale do Silício em português), na Califórnia. [...] Através do venture capital, Startup que pretendem crescer rápido e se transformar em grandes companhias passam a dispor de oportunidades para financiar o seu crescimento, com apoio para a criação de estruturas de governança, lucratividade e sustentabilidade futura do negócio.

Do mesmo modo, Ries (2012, p. 26) define Startup como sendo uma “[...] instituição humana projetada para criar novos produtos e serviços sob condições de extrema incerteza". Entretanto, não é tarefa fácil definir de modo preciso o termo startup, e Barbosa, Pimenta e Fonseca (2017, p.16) comentam sobre esta dificuldade:

[....] ainda é um desafio definir de modo preciso o que seja uma startup, contudo é possível perceber uma característica essencial que a distingue de qualquer outro tipo de negócio: alto e rápido potencial de escalabilidade, isto é, a capacidade de crescer vertiginosa e rapidamente.

Tarefa de menor complexidade é trazer as características específicas desse modelo de negócio, os quais, pode-se dizer que são essencialmente duas: primeiramente o seu fundamento em uma ideia tecnológica inovadora que cria ou melhora um produto ou serviço e, secundariamente, a sua inserção em um ambiente de grandes incertezas. Por essa razão, Sarmento e Costa (2016, p. 66.) defendem que esse modelo de negócio é de alto risco, possuindo uma grande imprevisibilidade na aceitação e viabilidade econômica dos seus produtos e serviços.

Note-se que as startups têm como característica o fundamento em uma ideia inovadora, sendo que essa inovação pode se dar com a criação ou melhoria de um bem ou serviço. Quando a inovação se refere à criação de algo totalmente novo, diz-se que é disruptiva; quando se refere à melhoria, diz-se que é incremental.

Muitas vezes o conceito de startup é confundido com o de micro e/ou pequena empresa, e isso é justificável, por não possuírem ainda no Brasil uma legislação tributária específica em vigor. Assim, as startups assumem a forma de micro ou pequena empresa e, nesse sentido, Nybo (2017) comenta que:

Embora frequentemente confundidos, esses conceitos não se misturam, uma vez que a definição de micro e pequena empresa está essencialmente atrelada ao seu faturamento para fins de definição de benefícios tributários e facilitação de processos burocráticos para empresas de menor porte. As startup, por outro lado, possuem uma dinâmica de negócios própria, baseada principalmente na inovação e tecnologia.

No Brasil, identifica-se que a primeira onda de interesse em startups aconteceu por volta de 
1998. Entretanto, logo depois desse movimento inicial, o interesse caiu e, por volta do ano 2000, poucos empreendimentos ainda sobreviviam. Uma nova onda de interesses em startups só veio ressurgir a partir de 2009, com a construção de um novo olhar sobre as atividades empresariais e sobre o empreendedorismo.

Acerca do tem, expõe Falcão (2017, p. 40-41) que:

No Brasil, a primeira onda que identificamos das Startups surgiu por volta de 1998, durante a bolha da Internet global. Depois do estouro, já por volta dos anos 2000, apenas alguns poucos empreendimentos sobreviveram. Muito pouco se fez em toda a América do Sul até que, em 2005, ocorre a venda da Akwan para o Google e, em 2009, a venda do Buscapé para a Naspers. Estas operações marcaram o início de uma onda de interesse por Startups em todo o Brasil, o que contribuiu para outros casos de sucesso.

Nos últimos anos, o número de startups no Brasil vem crescendo de forma exponencial, sendo que, no final de 2018, a STARTUP BASE, maior base online de dados relacionados às startup brasileiras, alcançou a marca de 10.000 (dez mil) startup mapeadas, para se ter ideia da importância dessa marca, é preciso destacar que em 2012 o número de startup mapeadas girava em torno de 2.519 (dois mil quinhentos e dezenove) e, em 2017, esse número era de aproximadamente de 5.147 (cinco mil cento e quarenta e sente). Já em agosto de 2019, o número de startups ultrapassou a marca de 13.000 (treze mil) (ABSTARTUPS, 2018).

No que diz respeito à captação de investimentos, tem-se que os chamados investidoresanjo são uma das principais formas pelas quais as startups obtêm capital. Essa modalidade de investimento foi regulamentada em 2016, com a Lei Complementar $\mathrm{n}^{\mathrm{o}} 155$, que alterou a Lei Complementar $\mathrm{n}^{\circ} 123$ de 2006, incluído o art. 61-A, que estabeleceu regras de responsabilização e direitos desse tipo de investidor (BRASIL, 2006, 2016). Entretanto, inexiste, no Brasil, incentivos fiscais para essa modalidade de investidor, o que faz com que as startups tenham dificuldade de conseguir capital investidor.

Mesmo com tais especificidades e dificuldades, muitas vezes no âmbito das startups há a necessidade de ser feito um planejamento interdisciplinar, com profissionais de diversas áreas como por exemplo, da administração, da área jurídica e da psicologia - de modo a não deixar que os colaboradores, e o próprio negócio, percam o foco de manter um ambiente que siga às regras morais, sociais e jurídicas, isso porque a startup não deve se distanciar dos preceitos da ética.

Desta forma, a partir do planejamento jurídico realizado, essencialmente nas startups de grande porte e de capital aberto, deve ser aplicado, obrigatoriamente, um estruturado sistema de compliance, de modo a garantir a transparência e a lisura, não apenas em relação ao poder público, como também para com seus clientes e investidores.

Sobre o tema, Gomiero (2019) evidencia que:

Esta nova sistemática de negócios não deve, contudo, se distanciar dos preceitos éticos e de compliance. Os programas de compliance podem ser definidos como 
o conjunto de princípios e regras estabelecidos para assegurar o cumprimento da legislação pelos colaboradores diretos e indiretos de uma entidade, bem como estabelecer mecanismos que promovam um ambiente corporativo ético e de respeito aos preceitos sociais.

Ainda que sem um incentivo pontual ou específico, que o Governo poderia fornecer às startups, empresas que assumem esse formato estão se destacando no mercado e ganhando bastante visibilidade e valoração monetária. No ano de 2018 a economia brasileira ganhou seu primeiro "unicórnio", atribuição dada à startup que passa a valer mais de US\$1.000.000.000 (um bilhão de dólares).

Brito (2018) destaca que "[...] o feito foi alcançado inicialmente pelo aplicativo de transporte 99 e pela Nubank, startup que gerencia serviços financeiros, avaliada em mais de U\$ 2. 000.000.000 (dois bilhões de dólares).”

A cada dia as startups vêm ganhando mais importância na economia brasileira, em 2017, os investimentos em startups brasileiras quebraram recordes em relação a 2016: houve um aumento de aproximadamente $300 \%$, de 926 milhões para 2,86 bilhões de reais (BIN, 2019). O mesmo ocorre quando o assunto é empregabilidade. Estima-se que as startups geram, no mínimo, algo em torno de 50 (cinquenta) mil novos postos de trabalho no país (ZAMBRANA, 2019, online), o que demonstra a importância desse tipo de negócio na economia brasileira, principalmente no que diz respeito à circulação de renda e geração de empregos.

\section{PLANEJAMENTO EMPRESARIAL E TRIBUTÁRIO PARA STARTUPS}

Mesmo com a grande importância que representam para a economia brasileira, as startups ainda possuem diversos problemas. Observa-se que as medidas para atender as necessidades específicas desse modelo de negócio surgem de forma muito demorada, o que, de certa forma, cria um entrave a essas empresas.

Para que se possa ter uma base, apenas em 24 de abril de 2019, houve a definição legal do conceito de startup. Neste momento, também lhe foi atribuido um Regime Tributário Especial, o Inova Simples. Isso aconteceu com o advento da Lei Complementar $n^{\circ} 167 / 19$ que, dentre outras coisas, alterou a Lei Complementar $n^{\circ} 123$, que como já mencionado anteriormente definiu micro e pequenas empresas e estabeleceu o regime tributário diferenciado para elas, o Simples Nacional). Acompanhe o que dispõe o artigo 65-A, da supracitada lei:

Art. 65-A. É criado o Inova Simples, regime especial simplificado que concede às iniciativas empresariais de caráter incremental ou disruptivo que se autodeclarem como startups ou empresas de inovação tratamento diferenciado com vistas a estimular sua criação, formalização, desenvolvimento e consolidação como agentes indutores de avanços tecnológicos e da geração de emprego e renda.

$\S 1^{\circ}$ Para os fins desta Lei Complementar, considera-se startup a empresa de caráter inovador que visa a aperfeiçoar sistemas, métodos ou modelos de negócio, de produção, de serviços ou de produtos, os quais, quando já existentes, 
caracterizam startups de natureza incremental, ou, quando relacionados à criação de algo totalmente novo, caracterizam startups de natureza disruptiva.

$\S 2^{\circ}$ As startups caracterizam-se por desenvolver suas inovações em condições de incerteza que requerem experimentos e validações constantes, inclusive mediante comercialização experimental provisória, antes de procederem à comercialização plena e à obtenção de receita (BRASIL, 2019).

Todavia, o referido dispositivo legal define em seu $§ 13$ que: “O disposto neste artigo será regulamentado pelo Comitê Gestor do Simples Nacional”, e essa regulamentação não tem data para acontecer, o que gera, ainda, grandes incertezas a respeito do nomeado Inova Simples.

Nota-se, assim, que os problemas relacionados à elevada carga tributária e à complexidade do Sistema Tributário Nacional são ainda mais graves no âmbito das startups, isso porque, como visto, não existe no Brasil um regime tributário específico em vigor para esse modelo de negócio, sendo necessário, atualmente, que as startups recolham seus tributos por meio do regime do Simples Nacional, do Lucro Presumido ou do Lucro Real, sistemas bem distintos e que não atendem integralmente as necessidade do modelo de negócio das startups.

O regime do lucro real, como o próprio nome aduz, é aquele no qual a tributação tem como base o lucro real da empresa, que é entendido como "[...] o lucro líquido do período apurado na escrituração comercial, denominado lucro contábil, ajustado pelas adições, exclusões e compensações autorizadas pela legislação do Imposto de Renda." (OLIVEIRA; CHIEREGATO; PEREZ JUNIOR, 2010, p. 562). Dos três em vigor, ele é o regime que detém maior complexidade. Todavia, algumas pessoas jurídicas são obrigadas a seguirem esse regime, conforme o art. 14 da Lei $n^{\circ} 9.718 / 98$.

Devido essa complexidade, é possível concluir que o regime do lucro real é incompatível com os ideais das startups, esses que, como já pode ser percebido, direcionam a atividade empresarial a um ambiente de rapidez, simplicidade e não burocratização.

O regime do lucro presumido, por sua vez, caracteriza-se por ser uma “[...] metodologia de apuração do Imposto de Renda e contribuição social que consiste numa forma simplificada de apuração do lucro tributável admitida para determinadas pessoas jurídicas e firmas individuais." (OLIVEIRA; CHIEREGATO; PEREZ JUNIOR, 2010, p. 561). Simplifica-se a apuração da base de cálculo, mas os tributos são pagos separadamente.

Assim, ainda que haja uma simplificação da base de cálculo, por haver a necessidade de pagamento dos tributos de forma separada, persiste o problema da complexidade do Sistema Tributário Nacional, não sendo esse regime, portanto o mais adequado para as startups.

O Simples Nacional é um regime especial aplicável às microempresas e às empresas de pequeno porte, tendo sido implantado pela LC $n^{0} 123 / 06$, constituindo-se como uma forma unificada de recolhimento de tributos por meio da aplicação de percentuais sobre a receita bruta (CUNHA, 2007). Dessa forma, ele é o que guarda menor complexidade, isso porque abrange os âmbitos federal, estatual e municipal, englobando diversos tributos.

Por essa simplificação, tal regime aparentemente é o que mais beneficia as startups. 
Entretanto, esse sistema traz restrições, por exemplo, apenas podem utilizar o referido regime as startups que possuírem a forma de microempresa ou empresa de pequeno porte, ou seja, as que forem constituídas como sociedade empresária, sociedade simples ou empresa individual de responsabilidade limitada e que, cumulativamente, aufiram, em cada ano-calendário, receita bruta de no máximo R $\$ 4.800 .000,00$ (quatro milhões e oitocentos mil reais), conforme preceitua do art. $3^{\circ}$ da LC 123/06. Além disso, o $\S 4^{\circ}$ da mesma lei traz outras restrições, como o fato de a empresa não poder possuir, como capital, receita proveniente de outra pessoa jurídica.

Com isso, pode-se dizer que, em uma primeira análise, o regime do Simples Nacional é o que guarda maior compatibilidade com as startups, entretanto, nem mesmo esse regime atende por completo as necessidades do modelo de negócio startup. Isso porque, por exemplo, não admite um crescimento empresarial muito acelerado (escalabilidade), por não permitir que a receita bruta anual da empresa supere a marca de $\mathrm{R} \$ 4.800 .000,00$ (quatro milhões e oitocentos mil reais). Ademais, não permite que a empresa mude seu tipo societário para se tornar uma S.A. (Sociedade Anônima), o que poderia facilitar a capitação de investimentos.

Conclui-se, dessa forma, que, se por um lado, devido a sua simplificação, o regime do Simples Nacional guarda compatibilidade com os startups, por outro, por conta das suas diversas restrições - que por vezes acaba engessando a atividade - essa compatibilidade é consideravelmente prejudicada, mesmo porque tal regime não foi criado para esse modelo de negócio.

Outro importantíssimo problema das startups, também relacionado à tributação, reside no fato de as empresas que adotam esse modelo de negócio, por vezes, trabalharem com as chamadas novas tecnologias, uma vez que não existe consenso se tais tecnologias devem ser tributadas como produtos ou como serviços.

\footnotetext{
Mas a dúvida sobre a tributação reside na seguinte pergunta: novas tecnologias são classificadas como mercadorias ou serviços? Temos de um lado da discussão os Estados que entendem que algumas tecnologias devem ser compreendidas como mercadorias ou serviços de comunicação (ambos tributados pelo ICMS, imposto de competência estadual). Do outro lado, temos os Municípios que defendem a classificação na categoria de serviços (e consequentemente tributadas pelo ISS, imposto de competência municipal) (TORRES, 2019).
}

Isso mostra a grande importância dos institutos de planejamento empresarial e tributário para as startups, que devem ser feitos antes do início das atividades da empresa, definindo questões relacionadas a, por exemplo, qual regime tributário será utilizado, qual será o setor específico de atuação e de quanto em quanto tempo será realizada a compra de insumos, mas não só isso...

O planejamento deve versar sobre toda a atividade que a empresa realizará, mostrando-se, na prática, uma atividade verdadeiramente complexa. Sobre o tema, Vieira (2017) comenta que o planejamento tributário, embora complexo quando é bem realizado, pode gerar uma enorme economia para a empresa.

Outro problema a ser trabalhado é a questão da importação de institutos estrangeiros como, exemplificativamente, a cláusula de vesting, que, uma vez mal redigida, poderá causar impactos 
severos de ordem tributária e mesmo trabalhista à startup.

A aludida cláusula, de origem norte-americana, estabelece um formato no qual os sócios adquirem um direito de participação após decorrido o lapso temporal prefixado entre as partes e que, como afirmam Júdice e Nybo (2016, p. 41): “[...] na hipótese de vencimento antecipado do período de vesting (por exemplo, pela retira do sócio) a startup poderá recomprar os títulos emitidos ao ex-sócio por seu valor de emissão.”

É importante frisar que na cláusula de vesting, o direito de participação do sócio é adquirido de uma única vez, e não de forma gradativa, pois, enquanto não decorrido todo o período estipulado, a empresa poderá recomprar os títulos emitidos ao ex-sócio à preço de emissão.

A tecnologia empresarial do mundo das startups, muitas vezes, é interpretada de forma equivocada no Brasil, levando a crer que a aquisição de participação, após o período de vesting, geraria obrigações previdenciárias e tributação pelo Imposto de Renda.

Júdice e Nybo (2016, p. 41) comentam acerca da impossibilidade dessas interpretações:

O direito de aquisição da participação acionária não deve ser visto como um ganho de capital e, por isso, não pode gerar o risco de tributação pelo Imposto de Renda, conforme pretendem erroneamente as autoridades brasileiras. A oferta condicionada de aquisição de participação societária também não deve gerar riscos previdenciários, por não se tratar de remuneração ou qualquer instituto de matéria trabalhista.

Não é tarefa fácil pensar em planejamento empresarial e tributário para startups, uma vez que as peculiaridades desse tipo de negócio influenciam diretamente em sua gestão. Por ter base inovadora, por exemplo, as empresas que seguem esse modelo de negócio, em regra, não possuem nenhum tipo de histórico operacional próprio nem no mercado. Dessa forma, torna-se impossível realizar um planejamento empresarial baseado em metas e estimativas exatas.

Nesse sentido, Ries (2018, p. 29) comenta acerca da sua experiência como empreendedor de startups do Vale do Silício:

As startups em que trabalhei e que conheci no Vale do Silício não podiam fazer estimativas exatas porque não tinham nenhum histórico operacional. Assim como seus produtos, seus mercados também eram desconhecidos - e, em certos casos, até a funcionalidade da própria tecnologia era desconhecida -, o eu impossibilitava qualquer estimativa exata.

Além disso, enquanto nas empresas que adotam um modelo de negócio tradicional o fracasso é visto como algo que nunca pode acontecer, gerando muitas vezes a dispensa dos líderes que tiveram ideias que fracassaram; nas startups, por possuírem como característica a sua inserção em um ambiente de grande imprevisibilidade, o fracasso deve sempre ser levado em consideração, não como um motivo de responsabilização dos líderes, mas como um instrumento de experiência, aprendizado e motivação de ideias inovadoras, o que no longo prazo têm muita chance de gerar ótimos frutos. 
Ries (2018, p. 35) muito bem observa que “[é] essa visão de longo prazo - o entendimento de que a limonada pode acabar não sendo um grande sucesso no longo prazo, mas alguma outra aposta pode ser - que permite a criação de um portfólio de experiências".

Assim, tendo em vista as peculiaridades do modelo de negócio startup, modo de ser e problemas específicos, percebe-se que para atender os seus anseios, o modelo tradicional de planejamento empresarial e tributário deve ser mudado. Isso porque tais planejamentos devem levar em consideração os referidos problemas peculiares enfrentados por esse tipo de negócio no Brasil, principalmente, reitera-se, no que concerne à falta de incentivos fiscais e à inexistência de um regime tributário específico para esse tipo de negócio.

Mais que isso, deve-se levar em consideração, também, as características particulares das startup e as dos institutos que eventualmente lhe acompanham, como a cláusula de vesting e o investidor-anjo.

Percebe-se que a criação de um planejamento empresarial e tributário de uma empresa requer a atuação de profissionais qualificados bem como um maior cuidado do planejador em relação ao ordenamento jurídico, o que fica mais latente quando a empresa possui base inovadora, como é o caso das startups. Nesse contexto, o advogado possui um papel de fundamental importância, assim:

O advogado não é o único vetor de inovação, por certo; mas é um profissional indispensável para que a concretização de estratégias de reformulação se faça de forma juridicamente correta e sustentável. Sem planejamento jurídico adequado, esses movimentos podem se revelar catastróficos (MAMEDE; MAMEDE, 2015, p. 1).

Deste modo, compete ao advogado elaborar, juntamente com o contador, um conjunto de estratégias que constituam um planejamento tributário que não se preocupe apenas com o ônus tributário do momento do planejamento, mas também, entre outras coisas, em criar uma forma de a empresa não sofrer com gastos tributários excessivos caso cresça muito e de forma rápida ou, em contraponto, que possa encerrar suas atividades sem maiores problemas tributários, caso não consiga se manter "viva", o que é comum para as startup, visto a imprevisibilidade desse tipo de negócio.

\section{CONSIDERAÇÕES FINAIS}

Como elucidado ao longo do artigo, o vocábulo "planejamento" pressupõe o binômio "objetivo e meios", primeiramente a definição de objetivos e, na sequência, a definição dos meios que serão utilizados para o alcance de tais objetivos. Por conta da finalidade econômica da atividade empresarial, têm-se que o planejamento empresarial possui como finalidade o aumento do lucro (menos débitos e mais créditos).

Com o objetivo de diminuir o ônus relacionado à tributação é que nasce a elisão fiscal, também denominado de planejamento jurídico tributário, que, na verdade, é uma forma de 
organizar as atividades realizadas pelo empresário de maneira lícita e sem abusos, com a finalidade de excluir, reduzir ou adiar os encargos tributários.

O mundo atual gera demandas cada vez mais complexas e que se modificam de forma bastante veloz. No anseio de atender tais demandas, surge o modelo de negócio denominado startup, que possui como características, primeiramente, o seu fundamento em uma ideia inovadora e, secundariamente, a sua inserção em um ambiente de grandes incertezas.

Como toda inovação, as startups enfrentam algumas dificuldades no Brasil e as medidas para atender tais dificuldades surgem de forma excessivamente lenta. Isso faz com que os problemas empresariais sejam mais severos no que diz respeito a esse modelo de negócio.

Um ponto que evidencia essa dificuldade é inexistência de um regime jurídico tributário específico no Brasil para esse tipo de negócio.

Por conta das características específicas das startups, como a sua imersão em um ambiente de grandes incertezas e o fundamento em uma ideia inovadora; e dos seus problemas peculiares, como a inexistência de um regime jurídico tributário específico para startups em vigor no país, a captação de investimento por meio do investidor anjo e a interpretação equivocada de institutos como a cláusula de vesting; é possível perceber que os modelos de planejamento jurídico empresarial e tributário a serem usados nesse tipo de negócio devem ser diferente dos usados em empresas tradicionais, isso porque estas últimas não precisam levar em consideração tais pontos no momento do planejamento.

Com isso, o planejamento empresarial e tributário direcionado para uma startup deve ser feito, como já mencionado ao longo do texto, antes do início de suas atividades, para definir regras essenciais, tais como: composição do capital social, utilização ou não da cláusula de vesting, especificações sobre de que forma será mantido o ambiente de criação, como serão trabalhados os riscos da atividade, além de definir qual dos regimes jurídico-tributários melhor atenderá as suas necessidades - se será o do Simples Nacional, o do Lucro presumido ou o do Lucro Real.

Assim, somente por meio de um planejamento empresarial e tributário adequado, que respeite as especificidades desse novo modelo negocial, é que as startups conseguirão atingir, de maneira lícita, os objetivos sociais e as metas econômicas almejadas.

\section{REFERÊNCIAS}

ABSTARTUPS. 2018: o ano que atingimos 10 mil startups mapeadas. Itforum, [s.l.], 2019. Disponível em: https://www.itforum365.com.br/colunas/2018-o-ano-que-atingimos-10-milstartups-brasileiras-mapeadas/. Acesso em: 10 fev. 2021.

ACKOFF, Russel L. Planejamento empresarial. Tradução de Marcos Túlio de Freitas. Rio de Janeiro: Livros Técnicos e Científicos S.A., 1974.

ALEXANDRE, Ricardo. Direito tributário. 11. ed. Salvador: JusPodivm, 2017.

ARAÚJO, Dayane de Almeida. Planejamento tributário aplicado aos instrumentos sucessórios. São Paulo: Almedina Brasil, 2018. 
BARBOSA, Anna Fonseca Martins; PIMENTA, Eduardo Goulart; FONSECA, Maurício Leopoldino da. Legal talks: Startups à luz do direito brasileiro. Porto Alegre, RS: Editora Fi, 2017.

BIN, Victor Hugo. Startups: a próxima bolsa de valores. São Paulo: Startse, 2019. Disponível em: https://www.startse.com/noticia/startups/60640/startup-proxima-bolsa-de-valores. Acesso em: 24 jan. 2021.

BORGES, Humberto Bonavides. Gerência de impostos: IPI, ICMS e ISS. 2. ed. São Paulo: Editora Atlas, 2011.

BRASIL. Lei complementar $n^{\mathbf{0}}$ 123, de 14 de dezembro de 2006. Institui o Estatuto Nacional da Microempresa e da Empresa de Pequeno Porte. Brasília: Presidência da República, 2006. Disponível em: http://www.planalto.gov.br/ccivil_03/leis/lcp/lcp123.htm. Acesso em: 20 jan. 2021.

BRASIL. Lei complementar $\mathbf{n}^{\mathbf{0}}$ 155, de 27 de outubro de 2016. Altera a Lei complementar no 123, de 14 de dezembro de 2016. Brasília: Presidência da República, 2006. Disponível em: http://www.planalto.gov.br/ccivil_03/leis/lcp/lcp155.htm. Acesso em: 29 dez. 2020.

BRASIL. Lei complementar $n^{\mathbf{0}}$ 167, de 24 de abril de 2019. Dispõe sobre a Empresa Simples de Crédito (ESC) e altera a Lei n ${ }^{\circ}$ 9.613, de 3 de março de 1998 (Lei de Lavagem de Dinheiro), a Lei $n^{\circ} 9.249$, de 26 de dezembro de 1995, e a Lei Complementar $n^{\circ} 123$, de 14 de dezembro de 2006 (Lei do Simples Nacional), para regulamentar a ESC e instituir o Inova Simples. Brasília: Presidência da República, 2019. Disponível em: http://www.planalto.gov.br/ccivil_03/leis/lcp/ Lcp167.htm. Acesso em: 29 dez. 2020.

BRASIL. Lei n⿳ 10.406, de 10 de janeiro de 2002. Institui o Código Civil. Brasília: Presidência da República, 2002. Disponível em: http://www.planalto.gov.br/ccivil_03/leis/2002/110406.htm. Acesso em: 29 dez. 2020.

BRASIL. Lei n⿳ 5.172, de 25 de outubro de 1966. Código Tributário Nacional. Brasília: Presidência da República, 1966, Disponível em: http://www.planalto.gov.br/ccivil_03/leis/15172. htm. Acesso em: 29 dez. 2020.

BREDA, Zulmir Ivânio. Estrutura tributária e qualidade dos gastos públicos. Brasília: Conselho Federal de Contabilidade, 2018. Disponível em: https://cfc.org.br/destaque/estruturatributaria-e-a-qualidade-dos-gastos-publicos. Acesso em: 29 dez. 2020.

BRITO, Débora. Startups crescem no Brasil e consolidam nova geração de empreendedores. Agência Brasil, Florianópolis, 14 jul. 2018. Disponível em: agenciabrasil.ebc.com.br/economia/ noticia/2018-07/startups-crescem-no-brasil-e-consolidam-nova-geracao-de-empreendedores. Acesso em: 2 dez. 2020.

COELHO, Fábio Ulhoa. Manual de direito comercial: direito de empresa. 23. ed. São Paulo: Saraiva, 2011.

CUNHA, Carlos Renato. O simples Nacional: reflexões sobre a tensão entre o argumento do fomento econômico, o interesse arrecadatório e a necessidade de respeito à Constituição Federal. In: ENCONTRO DE ESTUDOS TRIBUTÁRIOS, 2., 2007, Londrina. Anais [...]. Londrina, 
2007. Disponível em: http://www.idtl.com.br/artigos/226.pdf. Acesso em: 22 nov. 2020.

FALCÃO, João Pontual de Arruda. Startup law Brasil: o direito brasileiro rege mas desconhece as startups. 2017. 147 f. Dissertação (Mestrado em Direito) - Escola de Direito do Rio de Janeiro, Rio de Janeiro, 2017.

GOMIERO, Paulo Henrique. Ética e compliance no cenário de inovação e startups. Migalhas, [s.l.], 2019. Disponível em: https://www.migalhas.com.br/dePeso/16,MI308122,71043-Etica+e+ compliance+no+cenario+de+inovacao+e+startups. Acesso em: 22 nov. 2020.

JÚDICE, Lucas Pimenta; NYBO, Erik Fontenele. Natureza jurídica do vesting: como uma tradução errada pode acabar com o futuro tributário e trabalhista de uma startup. In: JÚDICE, Lucas Pimenta; NYBO, Erik Fontenele (org.). Direito das Startups. Curitiba: Juruá, 2016. p. $39-50$

MAMEDE, Gladston; MAMEDE, Eduarda Cotta. Holding familiar e suas vantagens. São Paulo: Editora Atlas, 2015.

MARTINS, Ives Gandra da Silva. Elisão e evasão fiscal. Revista Dialética de Direito Tributário, São Paulo, n. 225, p. 102-112, jun. 2014.

NYBO, Erik Fontenele. As startups e a ascensão de uma nova matéria no Direito. Consultor Jurídico, São Paulo, 14 abr. 2017. Disponível em: https://www.conjur.com.br/2017-abr-14/eriknybo-startups-ascensao-materia-direito. Acesso em: 30 dez. 2020.

OLIVEIRA, Luís Martins de; CHIEREGATO, Renato; PEREZ JUNIOR, José Hernandez; GOMES, Marliete Bezerra. Manual de contabilidade tributária: textos e testes com as respostas. São Paulo: Atlas, 2010.

RIES, Eric. A startup enxuta: como os empreendedores atuais utilizam a inovação contínua para criar empresas extremamente bem-sucedidas. São Paulo: LeYa, 2012.

RIES, Eric. O estilo Startup. Tradução de Carlos Szlak. Rio de Janeiro: LeYa, 2018.

SARMENTO, Marcela Regina Climaco; COSTA, Lúcia de Fátima Lúcio Gomes. O papel das aceleradoras na consolidação de novas empresas de cultura empreendedora a luz da metodologia lean startup. Empírica BR, Natal, v. 1, p. 65-86, 2016.

SIQUEIRA, Eurípedes Bastos; CURY, Lacordaire Kemel Pimenta; GOMES, Thiago Simões Gomes. Planejamento Tributário. Revista CEPPG, Catalão, v. 1, n. 25, p. 184-196, 2011.

TORRES, Ricardo Lobo. Planejamento tributário: elisão abusiva e evasão fiscal. Rio de Janeiro: Elsevier, 2013.

TORRES, Vitor. Tributação de novas tecnologias: entenda como funciona para startups. 2019. Contabilizei Blog, São Paulo, 1 set. 2020. Disponível em: https://blog.contabilizei.com.br/ tributacao-de-novas-tecnologias-e-startups. Acesso em: 12 jan. 2021.

VALE do Silício: como fazer parte, mesmo não estando lá. Endeavor, São Paulo, ago. 2019. Disponível em: https://endeavor.org.br/inovacao/vale-do-silicio. Acesso em: 22 dez. 2020. 
VIEIRA, Lucas Bezerra. Direito para startups: manual jurídico para empreendedores. Natal: Queiroz, Barbosa e Bezerra Advocacia, 2017.

ZAMBRANA, Luiza. O ecossistema de Startups se mantém aquecido e já são quase 3.000 vagas abertas em todo Brasil. Startupi, [s.l.], 2019. Disponível em: https://startupi.com.br/2019/01/oecossistema-de-startups-se-mantem-aquecido-e-ja-sao-quase-3-000-vagas-abertas-em-todoBrasil. Acesso em: 22 dez. 2020.

Como citar: SANTANA, Agatha Gonçalves; FERREIRA, Vanessa Rocha; SILVA, Reginaldo Costa da. Planejamento empresarial e tributário de Startups: definições e características específicas. Revista do Direito Público, Londrina, v. 16, n. 2, p. 126-143, ago. 2021. DOI 10.5433/24157-108104-1.2021v16n2p. 126. ISSN: 1980-511X

Recebido em: 17/02/2020

Aprovado em: 15/07/2021 